\title{
桐梓河流域输沙量变化及其对气候和 人类活动的响应
}

\author{
田义超 ${ }^{1,2,3,4}$, 王世杰 ${ }^{2}$, 白晓永 ${ }^{2}$, 张 强 ${ }^{1}$, 陶 进 ${ }^{1}$, 张亚丽 $^{1}$, \\ 黄 鹄 ${ }^{4}$, 梁铭忠 ${ }^{4}$, 周国清 ${ }^{5}$, 劳燕玲 ${ }^{1}$
}

(1. 北部湾大学资源与环境学院,钦州 $535000 ; 2$. 中国科学院地球化学研究所环境地球化学

国家重点实验室,贵阳 $550081 ; 3$. 海洋地理信息资源开发利用重点实验室,钦州 535000 ;

4. 北部湾大学广西北部湾海洋生物多样性养护重点实验室, 钦州 535000 ;

5. 桂林理工大学广西空间信息与测绘重点实验室,桂林 541004)

\begin{abstract}
摘要：基于桐梓河流域二郎坝水文站 1975-2015 年长时间序列降水、蒸散量及输沙量数据, 通 过累积距平法、Morlet 小波分析和 Hurst 指数等数理统计方法; 定量分析了流域 40 年以来输沙 量的演变过程以及未来变化趋势, 并应用累积量斜率变化率比较法定量评估了研究区降雨量 变化和人类活动对流域输沙量变化的影响和贡献率。研究结果表明:(1)40年来流域降水量介于 608.10 1132.70 mm之间, 其平均值为 $829.00 \mathrm{~mm}$, 呈不显著减小趋势, 年均减小量为 $-3.10 \mathrm{~mm} / \mathrm{a}$ 。 (2) 流域年输沙量介于 0.44 万 478.01 万 $\mathrm{t}$, 其平均值为 64.68 万 $\mathrm{t}$, 呈极显著减少趋势, 减少速 率为 -4.13 万 $\mathrm{t} / \mathrm{a}$ 。未来流域输沙量呈持续递减趋势, 但 10 年后将呈现出增加趋势。(3)1989年 为流域输沙量的突变年份, 1989年以前呈现上升趋势, 1989年之后呈显著下降趋势, 且突变年 份后输沙量较突变年份前减少了 $76.82 \%$ 。(4)输沙量存在 12 年左右的年代际震荡周期, 形成了 两个高震荡周期和一个低震荡中心, 高震荡周期位于 1976-1979年以及 1986-1992 年, 低震荡周 期位于 1979-1985 年。(5)多年季节输沙量呈持续性减少趋势, 夏季输沙量在 8 年之后可能呈现 出增加趋势, 而其他季节则不存在持续性周期。(6)以 1975-1989为基准期, 降水量和人类活动 对流域输沙量的贡献在 1990-2015 年分别达到 4.87\%和 95.14\% ; 如果考虑蒸发量对流域输沙量 的影响, 则人类活动对桐梓河流域径流量变化的贡献率在 2003-2015 年会增加到 $98.65 \%$ 。流域 输沙量在 $1990-2015$ 年的减少主要由人类活动控制, 人类活动每年导致输沙量减少 1.57 万 $\mathrm{t}$ 。
\end{abstract}

关键词: 输沙量;气候变化; 人类活动; 响应;桐梓河流域

水文水资源对气候变化和人类活动的响应是近年来气候学、水文学等相关领域的研 究热点。近百年来, 全球气候变化正在经历着以变暖为主要特征的显著变化 ${ }^{[1-3]}$ 。在全球 变暖的趋势下，区域或流域的暴雨、洪涝、强风暴潮、干早、高温热浪等极端气候事件 频繁发生, 影响着流域的水循环和水资源变化过程 ${ }^{[4-7]}$ 。以全球变暖为主要特征的气候变

收稿日期：2019-05-31；修订日期：2019-09-10

基金项目：国家重点研发计划（2016YFC0502300）；广西自然科学基金项目（2018JJA150135）; 广西教育厅基金项 目（ZD2014138）; 广西创新驱动发展专项（AA18118038）；广西北部湾海洋生物多样性养护重点实验 室、北部湾海洋生物资源开发与保护重点实验室联合资助项目（2015ZB07）；广西科技计划项目 (2017AB43024)

作者简介: 田义超（1986- ), 男, 陕西西安人, 博士, 工程师, 主要从事资源环境遥感与 GIS 及海岸带生态环境监 测的相关研究。E-mail: tianyichao1314@yeah.net

通讯作者: 白晓永 (1978-), 男, 河北石家庄人, 博士, 研究员, 主要从事岩溶生态环境研究。

E-mail: baixiaoyong@126.com 
化, 通过改变大气温度、降水继而影响区域或者陆地水循环过程, 并驱动流域径流、泥 沙等水文要素发生显著变化 ${ }^{[8]}$ 。气候变化对流域水沙的影响已成为水文学研究的前沿问题、 并且成为流域生态水文过程以及区域水土保持的关键科学问题。流域的水沙过程及其通 量在自然条件下主要受到气候系统的影响, 随着人类活动的影响以及社会经济的快速发 展, 全球、区域乃至流域的水沙通量, 尤其是流域的输沙量过程发生显著的变化 ${ }^{[0-11]}$ 。因 此, 针对气候变化和人类活动背景下流域水沙响应的精确预报, 开展气候变化特征及其 对流域输沙量的影响及其定量评估亟待进一步研究。

国内外学者从气候变化以及人类活动背景出发, 对区域或流域尺度上的输沙过程进 行了定量化研究并取得了丰硕的成果。关于流域输沙量的驱动力因素, 不同学者得出的 结论存在显著差异 ${ }^{[12-13]}$, 但其主要的观点认为输沙量的减少是气候与人类活动共同叠加的 结果 ${ }^{[14]}$, 只是降水和人类活动对输沙量的贡献率依据研究区的不同其结果存在显著的差 异。有研究表明全球 142 条河流有近一半 (49.3\%) 的输沙量都呈现出减少趋势, 其主要 的控制因素为气候变化 ${ }^{[12-13]}$ 。在中国的 8 大流域中, 降水量减少、气温升高会引起干旱区 流域的输沙量减少 $4 \%$ \% $61 \%$, 人类活动对流域输沙量的减少存在着显著的差异 ${ }^{[15]}$, 如黄 河流域 1997-2006 年期间实测输沙量较 1970 年以前年均减小 11.80 亿 $\mathrm{t}$, 人类活动的减沙 作用与降雨的影响基本相当 ${ }^{[16]}$, 然而在黄河流域子流域藉河流域的水文要素驱动因素 中, 人类活动影响的贡献率为 $90.2 \%$, 而气候变化贡献率仅为 $9.8 \%$ 。就干旱地区的黑 河流域中上游而言, 水文过程的变化以气候变化影响为主, 人类活动影响较小 ${ }^{\left[{ }^{[18}\right]}$ 。在湿 润热带与亚热带地区的喀斯特流域, 由于地表景观的高度异质性使得流域的产流和产沙 呈现出显著的时空差异性。喀斯特流域水文过程是气候、岩性、植被等因素综合作用的 结果，水文时间序列表现出高度非线性和多时间尺度特性，由于自然因素和人类活动作 用，喀斯特流域水文过程变化极其复杂 ${ }^{[19]}$ 。究其原因是人类活动改变了部分水循环，对 径流变化的影响最终反映在实际的蒸散量变化中, 导致气候因素和人类活动的影响比重 在发生改变 ${ }^{[20]}$ 。已有研究表明不同喀斯特流域降雨量对径流量变化的贡献率都维持在 $50 \% \sim 60 \%$ 的较高水平, 并且偏高于非喀斯特流域，除了多时间尺度特征影响外，还受到喀 斯特地表破碎，土层浅薄、土壤通透性高等水文地质结构和地形地貌的严重制约 ${ }^{[2-2]}$ 。目 前喀斯特流域已有的研究成果多集中在径流量对人类活动和气候变化的响应, 而对喀斯 特流域的输沙量对气候变化和人类活动的响应及其贡献率目前尚不明晰, 因此, 查明喀 斯特流域输沙量的变化特征和变化趋势, 分析其变化原因, 量化气候变化和人类活动对 输沙量的贡献率对于流域的水土保持工作以及水资源管理具有重要的意义。

处于贵州大娄山山脉西侧的桐梓河流域，是赤水河流域最大的支流，河流流向自西 向东, 属于典型的喀斯特流域。 20 世纪 60 年代人类活动对流域进行陡坡开荒、乱砍乱伐 导致水土流失, 经过 “十一五” “十二五” 期间大规模的实施退耕护岸林、封山育林以及 石漠化等生态工程的实施，区域的土地利用发生了显著变化，直接影响流域的径流和泥 沙形成过程。但是目前针对该流域输沙量的时空变化特征, 未来变化趋势及其对气候变 化的响应机理尚不可知, 同时该流域气候变化和人类活动对输沙量的贡献率目前也未见 报道。因此, 如何定量化评估气候变化和人类活动对典型喀斯特流域输沙量的影响及其 程度, 并定量评估其主要影响因素, 成为喀斯特流域水资源研究和管理亟待解决的一个 重大难题, 在国际上, 针对典型喀斯特地区输沙量的相关数据、技术方法及生态工程对 输沙量影响的评估较少。基于此, 本文以桐梓河流域为研究对象, 基于二郎坝水文监测 
断面长时间序列的水文气象监测资料，通过累积距平法、连续小波分析法、滑动 $\mathrm{T}$ 检验 方法和 Hurst 指数定量分析流域近 40 年以来输沙量的演变特征和未来趋势，并应用累积 量斜率变化率比较法定量评估研究区气候变化和人类活动对输沙量变化影响的贡献率。 本研究不仅意义重大，同时为桐梓河流域新时期水土保持工作，生态环境建设、水资源可 持续利用以及流域生态系统可持续性管理等工作的开展提供数据支撑和理论依据。

\section{1 研究方法与数据来源}

\section{1 研究区概况}

桐梓河流域属于典型的喀斯特流域，是赤水河流域最大的支流。流域面积 $3348 \mathrm{~km}^{2}$, 发源于天门河，随后流经天门洞、蟠龙洞、混子河口、观音寺河、石嘴，最后注人赤水 河。流域海拔高程为 484 1843 m（图 1)，沿河都是崇山峻岭，多悬岩崩石，发源地天门 属于冲积盆地, 其余地区属于典型喀斯特地区的特点, 耕地少而分散, U 形河谷发育, 宽度 $80 \mathrm{~m}$ ，河谷两旁陡峭。流域人类活动主要以农业活动为主，农业人口 59.92 万人， 总人口 64.86 万人。中亚热带季风气候是该流域主要气候类型，气候温和湿润，降雨量大 但分布不均, 多年平均气温 $17.7^{\circ} \mathrm{C}$, 多年全年积温 $5392{ }^{\circ} \mathrm{C}$ 。该流域的降水量和径流量的 变化规律基本保持一致, 属于非常典型的雨源型河流。流域土地利用以耕地和林地为 主，灌木林地分布于流域的中下游区域，黄壤和石灰（岩）土是研究区的主要土壤类 型。流域出露地层有震旦系、三叠系、第四系等，上游地区以古生代二叠系、三叠系地层 为主，石灰岩分布面宽广，夹有页岩和煤系。

长期的碳酸盐风化以及人类活动对区域植被的影响是导致流域输沙量变化的主要 原因。流域内的人类活动通过改变地表覆被类型以及筑坝工程对泥沙的拦截作用使得流 域输沙量呈现出下降趋势。人类活动通过改变地表覆盖类型致使流域NDVI呈现出增加 趋势，增加的区域所占的面积达到 78.2\%（图 1)。由于桐梓河流域的天门河水库、九盆 水水库、火石水库以及高坎水库等其他 20 余座中小型水库的拦沙作用，导致流域输沙量
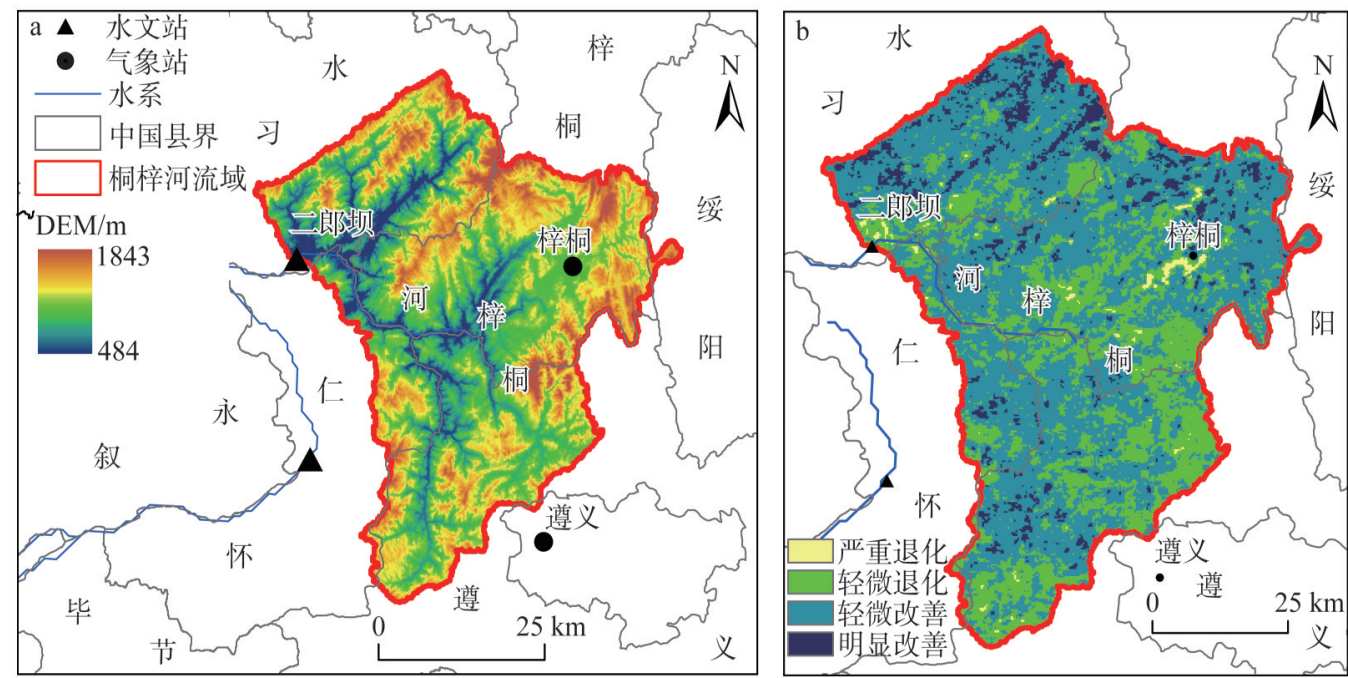

图 1 桐梓河流域空间位置及其植被 NDVI变化

Fig. 1 Spatial location and NDVI change of vegetation in Tongzi River Basin 
呈现减少趋势。其中天门河水库工程水库建于 2001 年, 是以县城防洪为主, 兼灌溉和供 水为主的典型中型水库, 该水库位于桐梓县城东北面小西湖上游, 地处赤水河水系桐梓 河支流上游天门河，址以上流域面积 $203 \mathrm{~km}^{2}$, 河长 $22.6 \mathrm{~km}$, 河道平均坡降 $9.1 \%$ ，坝址 处多年平均流量 $3.82 \mathrm{~m}^{3} / \mathrm{s}$, 多年平均径流量 12050 万 $\mathrm{m}^{3}$, 多年平均输沙量 12.18 万 $\mathrm{t}$, 多 年平均含沙量 $0.849 \mathrm{~kg} / \mathrm{m}^{3}$, 多年平均悬移质输沙率 $3.224 \mathrm{~kg} / \mathrm{s}$ 。

\section{2 数据来源}

本文输沙量数据为桐梓河流域二郎坝水文站的断面监测数据, 时间尺度为 1975-2015 年的月实测数据。由于二郎坝水文站输沙量的原始数据为平均输沙率, 单位为 $\mathrm{kg} / \mathrm{s}$, 该 研究将其乘以每年的总时间可得到不同年份的输沙量数据, 其单位为 $\mathrm{t}$, 数据来源于贵州 省水文水资源局（http: //www.gzswj.gov.cn/hydrology_gz_new/index.html）。由于桐梓河流 域气象站点十分稀少, 选用的气象数据来源于流域中的桐梓国家基本气象台站资料 (http: //data.cma.cn/)。流域中的气象数据主要包括月降水量和月蒸散量数据, 为了确保 分析结果的一致性和连续性，其时间跨度与径流量保持一致，为 1975-2015年。由于流域 面积较大, 文中的降水量定义为桐梓、遵义以及二郎坝水文站多年降水量的平均值。 NDVI变化趋势数据来源于 2000-2015 年的 MOD13Q1 中的植被 NDVI数据, 空间分辨率 为 $250 \mathrm{~m}$ ，时间分辨率为 16 天。

\section{3 研究方法}

\subsection{1 输沙量变化趋势监测方法}

累积滤波器方法是一种检测水文时间序列变化趋势的分析方法，本研究利用累积滤 波器分析方法计算长时间序列输沙量的增加或减少趋势 ${ }^{[23]}$, 该方法定义长时间序列泥沙 量的累积平均值 $S$ 为:

$$
S=\frac{\sum_{i=1}^{n} D_{i} / n^{\prime}}{\bar{D}}
$$

式中: $S$ 代表时间序列的累积平均值; $D_{i}$ 表示流域的年输沙量; $n$ 代表时间序列的长度， $n^{\prime}=1,2, \cdots, n ; \bar{D}$ 代表多年输沙量的平均值。

1.3.2 非参数 Sen 趋势与统计检验方法

本文采用 Sen 趋势度分析方法对流域输沙量突变前后的变化趋势进行诊断, 并通过 Mann-Kendall 对其显著性水平进行统计分析 ${ }^{[24]}$ 。该方法中的数据样本不必要遵循一定的 分布规律，且不受异常值的影响。Sen趋势度 $(\rho)$ 计算公式为:

$$
\rho=\text { median } \frac{x_{j}-x_{i}}{j-i}, \quad 1<i<j<n
$$

式中: $x_{i} 、 x_{j}$ 为水文输沙量时间序列。当 $\rho<0$ 时, 表示时间序列呈下降趋势, 当 $\rho>0$ 时, 表 示时间序列呈上升趋势。Kendall统计检验方法的基础是统计量 $\mathrm{M}$ ，当输沙量时间序列长 度增加时, $M$ 值很快收玫于标准正态分布, 对于 $a=5 \%$ 的显著性水平, 若 $|M|>M a=1.96$, 则表明时间序列具有显著变化趋势。

\subsection{3 输沙量突变年份检验}

该方法是由数据的累积距平值在曲线的变化过程来判断时间序列数据突变年份的一 种统计方法 ${ }^{[25]}$ 。定义于时间序列 $x$, 在某一时刻 $t$ 内的累积距平表示为: 


$$
X_{t}=\sum_{i=1}^{t}\left(x_{i}-\bar{x}\right)
$$

式中: $\bar{x}$ 代表多年输沙量的平均值; $i$ 和 $t$ 分别输沙量的时间序列, 该方法的主要思想 是判别数据对于平均值的偏离程度, 如果累积距平的数值大, 说明其数据的离散程度 高于平均值，反之则小于平均值，曲线的变化如果刚好由两部分构成，则说明该时间 序列数据存在明显的拐点, 此拐点则为突变点。

\subsection{4 输沙量未来持续性时间}

重新标度极差分析法（Rescaled Range Analysis Method，R/S）是由英国水文学家 Hurst ${ }^{[26]}$ 最先提出, 随后, Mandelbrot 等 ${ }^{[27]}$ 对该方法进行了改进, 目前已成为生态学、气 候学、水文学及经济学中重要的实现序列分析方法。

给定一时间序列 $\{\xi(t)\}, t=1,2, \cdots$, 对于任意正整数 $\tau \geqslant 1$, 定义均值序列:

$$
\langle\xi\rangle_{\tau}=\frac{1}{\tau} \sum_{t=1}^{\tau} \xi(t) \quad \tau=1,2, \cdots
$$

(1) 累积离差:

$$
X(t, \tau)=\sum_{u=1}^{t}\left(\xi(u)-\langle\xi\rangle_{\tau}\right) \quad 1 \leqslant t \leqslant \tau
$$

(2) 极差:

$$
R(\tau)=\max _{1 \leqslant t \leqslant \tau} X(t, \tau)-\min _{1 \leq t \leq \tau} X(t, \tau) \quad \tau=1,2, \cdots
$$

(3) 标准差:

$$
S(\tau)=\left[\frac{1}{\tau} \sum_{t=1}^{q}\left(\xi(t)-\langle\xi\rangle_{\tau}\right)^{2}\right]^{\frac{1}{2}} \quad \tau=1,2, \cdots
$$

对 $R / S$ 变量值进行无量纲化计算, 即:

$$
\frac{R(\tau)}{S(\tau)}=\frac{\max _{1 \leqslant t \leqslant \tau} X(t, \tau)-\min _{1 \leqslant t \leqslant q} X(t, \tau)}{\left[\frac{1}{\tau} \sum_{t=1}^{\tau}\left(\xi(t)-\langle\xi\rangle_{\tau}\right)^{2}\right]^{\frac{1}{2}}} \quad \tau=1,2, \cdots
$$

若 $R(\tau) / S(\tau) \cong R / S$ 存在, 即 $R / S \propto \tau^{H}$ 存在, 则表明输沙量存在 Hurst 现象, $H$ 称为 Hurst 指数，该值可通过对 $\ln \tau$ 和 $\ln R / S$ 使用最小二乘法拟合，其中 $\tau$ 代表时间序列的序号值 $(\tau \geqslant 1)$ 。若 $0.5<H<1$, 表明数据在未来呈现出持续趋势; 若 $H=0.5$, 表明数据未来呈现随 机状态; 若 $0<H<0.5$, 表明数据未来呈现反持续状态, 本研究使用 $H$ 指数揭示年季输沙 量的末来变化趋势。

为了定量描述输沙量长时间序列数据未来变化趋势的平均循环周期，引入统计量 $V(\tau)$, 计算公式如下:

$$
V(\tau)=\left[\frac{R(\tau)}{S(\tau)}\right]_{\tau} / \sqrt{\tau}
$$

$V(\tau)$ 为 $R / S$ 时间序列结果的稳定性，该变量可定量甄别长时间序列数据是否存在周期 循环性特征。

构建统计 $C(V(\tau)-\log (\tau))$ 曲线，其中 $\log (\tau)$ 表示对时间序列取对数，如果 $C(V(\tau)-\log (\tau))$ 曲线上 $V(\tau)$ 随 $\log (\tau)$ 的变化趋势发生显著变化，即时间序列从曲线发生的转折点可以识别 出周期，该周期的时间跨度 $t$ 就是时间序列数据未来的平均循环周期 $T$ 。对于独立随机过 
程的时间序列数据来说, 统计量 $V(\tau)-\log (\tau)$ 曲线接近平缓; 如果 $H>0.5, V(\tau)-\log (\tau)$ 曲线 则向上倾斜; 反之, $H<0.5, V(\tau)-\log (\tau)$ 曲线则表现出向下倾斜趋势。

\subsection{5 输沙量周期诊断}

本文基于流域长时间序列泥沙数据，采用Morlet 小波分析进行变化周期研究 ${ }^{[29]}$ 。其 中，小波分析是一种时、频多分辨分析方法，能够很好地揭示时间序列的不同时间尺 度上的局部变化特征。本文采用 Morlet 小波方法对流域的年输沙量时间序列进行小波变 换, 通过变换得到输沙量的小波系数和小波方差。后者反映了能量随尺度的分布特征, 方差值的峰值由大到小对应着的不同的主周期，可用来描述一个时间序列中所存在的主 要时间尺度。

\subsection{6 气候变化和人类活动对输沙量贡献率识别}

王随继等 ${ }^{[28]}$ 提出的累积量斜率变化率分析方法的理论原理为：以水文时间序列数据 如泥沙量的年份数据为自变量, 各因子如降水量的累积量为因变量进行斜率变化率分 析。假设流域的降水量为 $P$, 累积降水量与年份之间的一次线性回归方程在突变前后的 斜率分别为 $S_{p a}$ 和 $S_{p b}$, 其单位为 $\mathrm{mm} / \mathrm{a}$; 流域的蒸发量为 $E$, 累积蒸发量与年份之间的一次 线性回归方程在突变点前后的斜率分别为 $S_{e a}$ 和 $S_{e b}$, 其单位为 $\mathrm{mm} / \mathrm{a}$; 流域的输沙量为 $D$, 累积输沙量与年份之间的一元线性回归方程在突变前后的斜率分别为 $S_{d a}$ 和 $S_{d b}$, 其单位为 $\mathrm{t} / \mathrm{a}$ 。则降水量对输沙量变化的贡献率为 $C_{p}$, 单位为百分比, 公式可表述为:

$$
C_{p}=100 \times\left(\left|S_{p a} / S_{p b}\right|-1\right) /\left(\left|S_{d a} / S_{d b}\right|-1\right)
$$

蒸散发量对输沙量的变化的贡献率 $C_{e}$, 单位为百分比, 公式可表述为:

$$
C_{e}=100 \times\left(\left|S_{e a} / S_{e b}\right|-1\right) /\left(\left|S_{d a} / S_{d b}\right|-1\right)
$$

分别计算以上两个公式的贡献率，依据以下公式可以计算出人类活动对输沙量的贡 献率:

$$
C_{h}=100-C_{p}-C_{e}
$$

\section{2 结果分析}

\section{1 桐梓河流域降水量年际变化特征}

\section{1 .1 年际变化及其阶段特征}

桐梓河流域二郎坝水文站 1957-2015 年不同年代降水量变化特征见表 1 。流域多年平 均降水量为 $829.00 \mathrm{~mm}$, 年际变差系数为 0.17 , 年际变化波动较小。最大降水量为 $1132.70 \mathrm{~mm}$, 出现在 1990 年, 极小值为 $608.10 \mathrm{~mm}$, 出现在 2011 年。各代际降水量整体 上呈现出降低趋势，其中 1975-2010年降水量下降幅度较小，其值由 20 世纪 70 年年代的 $864.58 \mathrm{~mm}$ 下降到 21 世纪前十年的 $828.77 \mathrm{~mm}$, 下降了 4.14\%。流域降水量自 2011 年以后 呈现出显著减少趋势, 由 21 世纪前十年的 $828.77 \mathrm{~mm}$ 减少到 2010-2015 年的 $740.83 \mathrm{~mm}$, 减少了 $10.61 \%$ 。流域降水量变差系数的波动范围为 $0.12 \sim 0.24$, 其中 2011-2015 年最大, 而 2000-2010变差系数最小。极值比是反映降水量最大值与最小值之间的比值大小, 其值 越大，代表降水量的年际变化越大。由表 1 可知，1990-1999年以及2011-2015 年之间的 极值比较大，其值分别为 1.86 和 1.78 ，说明该时期降水量的年际变化差异较大。

\section{1 .2 年际变化趋势及其阶段特征}

由流域多年降水量的变化趋势图 2 可知, 自 20 世纪 70 年代以来多年平均降水量呈现 
出减少趋势, 减少的速率为 $-3.10 \mathrm{~mm} / \mathrm{a}$, $P$ 值为 0.09 , 没有达到显著性水平为 0.05 的水平, 说明桐梓河流域降水量变化呈 现出不显著减少趋势。20世纪 90 年代桐 梓河流域的多年平均降水量高于平均 值，20世纪 90 年代以前多年平均降水量 波动幅度较大，而在 20 世纪 90 年代之后 降水量变幅较小。1990年的流域降水量 达到了多年降水量的最大值，而1993年 则为多年的最小值。从降水量五年滑动
表 1 桐梓河流域不同阶段降水量统计特征

Table 1 Statistical characteristics of precipitation in different stages in Tongzi River Basin

\begin{tabular}{cccc}
\hline 时段/年 & 平均值 $/ \mathrm{mm}$ & 极值比 & 变差系数 \\
\hline $1975-1979$ & 864.58 & 1.64 & 0.18 \\
$1980-1989$ & 845.01 & 1.57 & 0.15 \\
$1990-1999$ & 848.35 & 1.86 & 0.20 \\
$2000-2010$ & 828.77 & 1.45 & 0.12 \\
$2011-2015$ & 740.83 & 1.78 & 0.24 \\
多年平均 & 829.00 & 1.86 & 0.17 \\
\hline
\end{tabular}
平均曲线来看，流域年降水量在 21 世纪之前丰枯明显，呈现出微弱下降趋势，2002年以 后降水呈现出显著下降趋势。
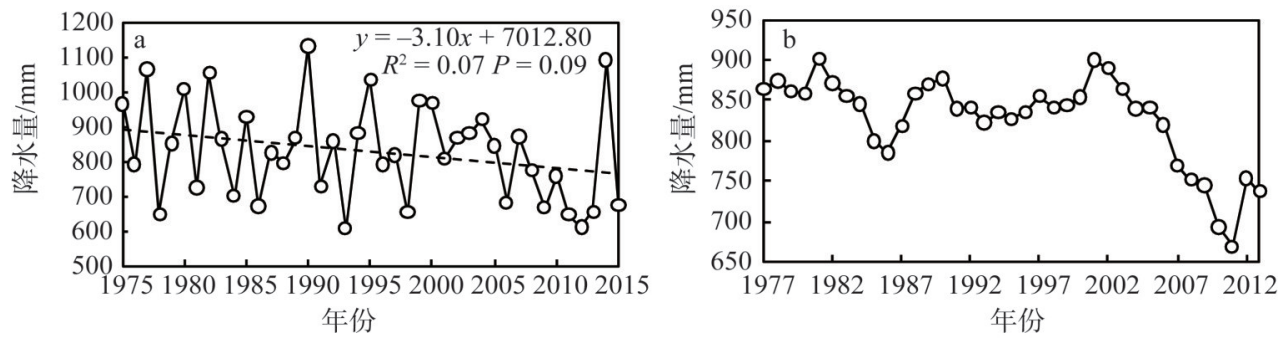

图 2 桐梓河流域降水量年际变化趋势及其滑动平均值变化特征

Fig. 2 Interannual variation trend and moving average characteristics of precipitation in Tongzi River Basin

\section{2 桐梓河流域输沙量年际变化特征}

\subsection{1 年际变化及其阶段特征}

桐梓河流域二郎坝水文站 1957-2015 年不同年代输沙量统计特征值见表 2。流域多年 输沙量为 64.68 万 $\mathrm{t}$, 年际变差系数为 1.33 , 输沙量年际变化波动强烈。最大输沙量为 478.01 万 $\mathrm{t}$, 出现在 1977 年，最小值为 0.44 万 $\mathrm{t}$ ，出现在 2012 年。各代际输沙量整体上呈现 出三个阶段，其中，1975-1989年呈下降趋势，其值由 20 世纪 70 年代的 647.58 万 $\mathrm{t}$ 下降到 20 世纪 80 年代的 581.11 万 $\mathrm{t}$; 流域输沙量自 20 世纪 80 年代后呈现出急剧增长趋势， 90 年 代达到历史时期的最大值，其值为 692.59 万 $\mathrm{t}$; 之后呈现出急剧减少趋势，其值由 90 年 代的 692.59 万 $\mathrm{t}$ 减少到 2010-2015 年的 218.75 万 $\mathrm{t}$ 。流域输沙量变差系数的变动 范围为 $0.38 \sim 1.99 ， 2011-2015$ 年输沙量 的变差系数变化最大, 其值为 1.99 , 说 明2011-2015年输沙量变化剧烈。从表 2 输沙量的极值比可知，1975-1979年以及 2011-2015 年间的极值比较大，其值分别 为 0.96 和 1.99 , 说明该时期输沙量的年 际变化差异较大。

\section{表 2 桐梓河流域不同阶段输沙量统计特征}

Table 2 Statistical characteristics of sediment transport in Tongzi River Basin in different stages

\begin{tabular}{cccc}
\hline 时段/年 & 年均输沙量/万 $\mathrm{t}$ & 极值比 & 变差系数 \\
\hline $1975-1979$ & 647.58 & 11.25 & 0.96 \\
$1980-1989$ & 581.11 & 6.65 & 0.38 \\
$1990-1999$ & 692.59 & 19.89 & 0.91 \\
$2000-2010$ & 272.72 & 14.99 & 0.93 \\
$2011-2015$ & 218.75 & 85.35 & 1.99 \\
多年平均 & 64.68 & 1084.89 & 1.33 \\
\hline
\end{tabular}




\subsection{2 年际变化趋势及其阶段特征}

由桐梓流域年输沙量的变化趋势图 3 可以看出, 二郎坝水文站输沙量自 20 世纪 70 年 代以来呈减少趋势, 减少的速率为 -4.13 万 $\mathrm{t} / \mathrm{a}, P$ 值小于 0.001 , 达到了极显著下降水 平，说明桐梓河流域输沙量在历史时期呈现出极显著减少趋势。2000年以前流域的多年 输沙量高于平均值，输沙量变幅较大，2000年以后多年输沙量波动幅度较小，呈减少趋 势。1977年的输沙量达到了多年输沙量的最大值，而2012年则为多年的最小值。由输沙 量五年滑动平均曲线可知，流域年输沙量在 20 世纪 80 年代之前呈现急剧减少趋势，80 年代到 90 年代中期呈现出微弱减少趋势, 进人 20 世纪后输沙量呈显著下降趋势。
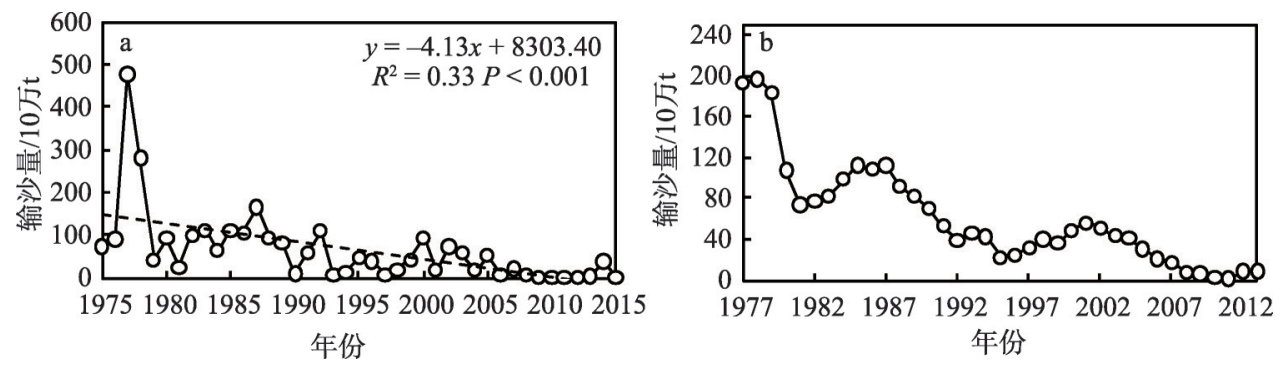

图 3 桐梓河流域输沙量年际变化趋势及其阶段性特征

Fig. 3 Interannual variation trend and moving average characteristics of sediment discharge in Tongzi River Basin

\subsection{3 输沙量 Hurst 指数及其可持续性}

由桐梓河流域多年输沙量统计表 3 可知, Kendall 秩序相关系数检验的 $M$ 值为 4.96, 说明桐梓河流域输沙量在 1975-2015 年期间呈现显著减少趋势。多年输沙量的 Hurst 指数 的 $H$ 值为 0.82 , 说明流域未来泥沙量变化与历史时期保持相同的趋势, 即流域未来年份 的输沙量呈现出持续性显著递减的趋势。结合 $M$ 值与 Hurst 指数值进行分析，若流域的气 候变化和人类活动保持现在的变化趋势或者输沙量变化更为剧烈时, 流域的输沙量仍然 继续保持显著递减状态。从桐梓河流域年输沙量变化持续性的周期图 4 中可以看出二郎 坝水文站输沙量时间序列在 10 年（曲线出现明显转折点的位置）呈现出明显的拐点，说 明输沙量的时间序列的平均循环周期 $T$ 值为 10 年， $T$ 值表征了流域输沙量时间序列系统 对初始条件的平均记忆长度, 说明流域输沙量在 10 年后可能呈现出增加的趋势。

表 3 桐梓河流域年输沙量变化趋势及其检验

Table 3 Trend and test of annual average sediment discharge in Tongzi River Basin

\begin{tabular}{|c|c|c|c|c|c|c|c|c|}
\hline \multirow{2}{*}{ 水文站 } & \multicolumn{4}{|c|}{ Kendall秩相关系数 } & \multirow{2}{*}{ 累积滤波器法 } & \multirow{2}{*}{ Hurst 指数 } & \multirow{2}{*}{ 未来趋势 } & \multirow{2}{*}{ 持续时间/年 } \\
\hline & $M$ 值 & 趋势 & $M a=0.05$ & 显著性 & & & & \\
\hline 二郎坝 & 4.96 & 下降 & 1.96 & 显著 & 减少 & 0.82 & 持续减少 & 10 \\
\hline
\end{tabular}

\section{3 桐梓河流域输沙量突变及周期性特征}

\subsection{1 输沙量突变特征}

根据桐梓河流域多年输沙量的累积距平曲线图 5 可知，二郎坝水文站多年输沙量的 变化具有明显的阶段性特征。多年输沙量累积距平值在 1989年达到最大值，表明桐梓河 流域的输沙量累积距平值在 1989年发生突变，由此可知流域的降水一输沙量关系可能发 生了改变，因此本文将流域的输沙量分为两个阶段，分别为 1975-1989年（多年输沙量为 

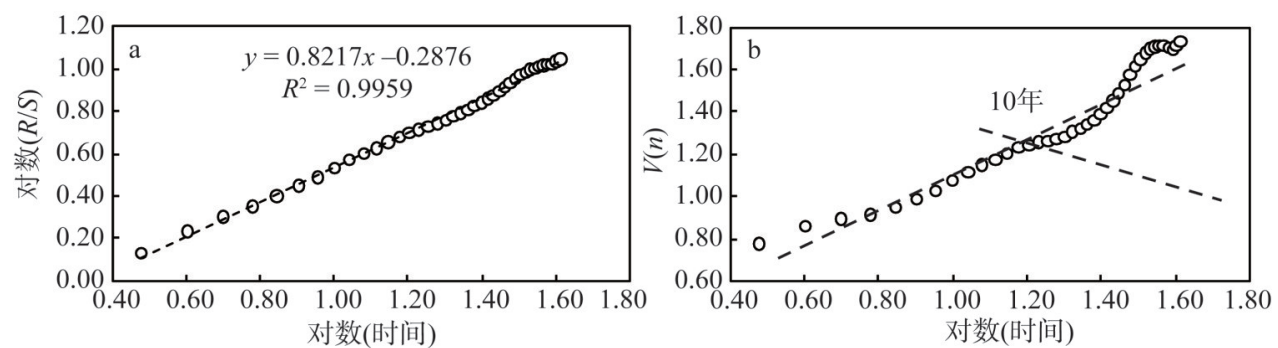

图 4 桐梓河流域平均输沙量变化 Hurst 指数及其持续性周期

Fig. 4 Hurst index and its continuous cycle of mean sediment discharge in Tongzi River Basin
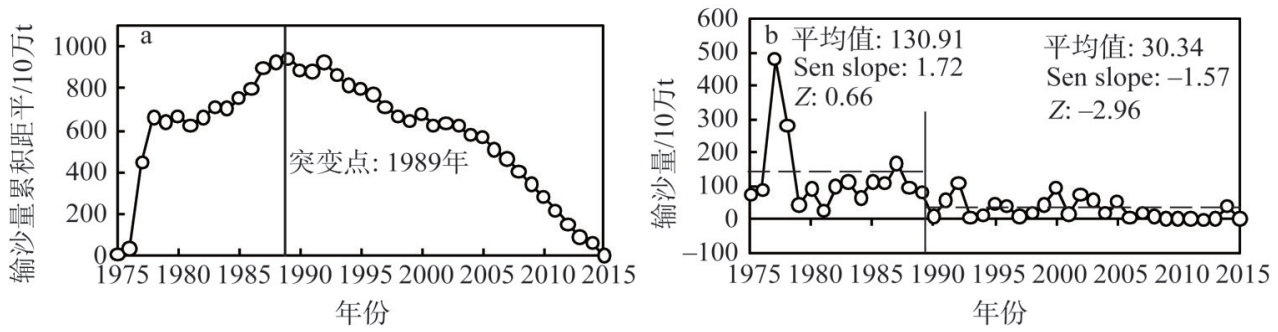

图 5 桐梓河流域年输沙量累积距平曲线和年平均输沙量突变特征

Fig. 5 Cumulative anomaly curve and abrupt characteristics of annual sediment discharge in Tongzi River Basin

130.91 万t ) 和 1989-2015 年两个阶段（多年输沙量为 30.34 万 $\mathrm{t}$ ), 突变年份后输沙量较突 变年份前减少了 $76.82 \%$ 。为了从不同角度验证该研究检测出的突变年份，本文使用 Sen 趋势方法计算出的突变年份同样为 1989年，以 1989年为基准点，分别对突变点前后桐梓 河流域的输沙量进行趋势分析。从图 5 可知，1989年以前流域输沙量的上升速率为 1.72 万 $\mathrm{t} / \mathrm{a}, 1989$ 年以后下降速率为 -1.57 万 $\mathrm{t} / \mathrm{a}$, 且突变年份后输沙量达到了 0.05 的显著性水 平（Z值大于 $1.96 ）$, 说明桐梓河流域输沙量自 1989年以后呈现出极显著减少趋势。

\subsection{2 输沙量周期特征}

为了更进一步研究桐梓河流域输沙量的周期性特征，借助 Matlab 2009 a工具箱中的 Morlet 小波分析工具对流域的输沙量进行周期分析并在此基础上绘制小波方差（图 6）。 二郎坝水文站输沙量在不同的时间尺度上呈现出丰枯交替变化的特征，主要表现为 5 15 年的震荡周期。其中 5 15 年的震荡周期信号能量相对较强，周期性最为明显。具体来说输 沙量在 12 年左右的年代际变化的震荡周期最为显著, 形成了两个高震荡周期和一个低震 荡中心，高震荡周期位于 1976-1979年以及1986-1992年，输沙量在该时期内呈现出正相 位，表明输沙量偏多；而1979-1985 年输沙量呈现出负相位，表明年输沙量偏少。从小波 方差图 6 可知, 输沙量的小波图在 12 年达到了最大值, 说明 12 年是桐梓河流域输沙量变化 的主周期。

\section{4 桐梓河流域径流量季节变化特征}

由桐梓河流域多年季节输沙量的变化曲线图 7 以及统计表 4 中可知，流域多年季节输 沙量都呈现出减少趋势, 递减趋势的大小趋势分别为秋季（2.5755 万 $\mathrm{t} / \mathrm{a} ）>$ 夏季（1.2930 万 $\mathrm{t} / \mathrm{a})>$ 冬季 $(0.2895$ 万 $\mathrm{t} / \mathrm{a})>$ 春季 $(0.0012$ 万 $\mathrm{t} / \mathrm{a})$ 。通过 Kendall检验可知, 夏季、秋季 和冬季的年输沙量 $M$ 值分别为 4.67、4.70 和 4.25, 不仅达到了 $Z$ 值为 $1.96(P=0.05)$ 的显 

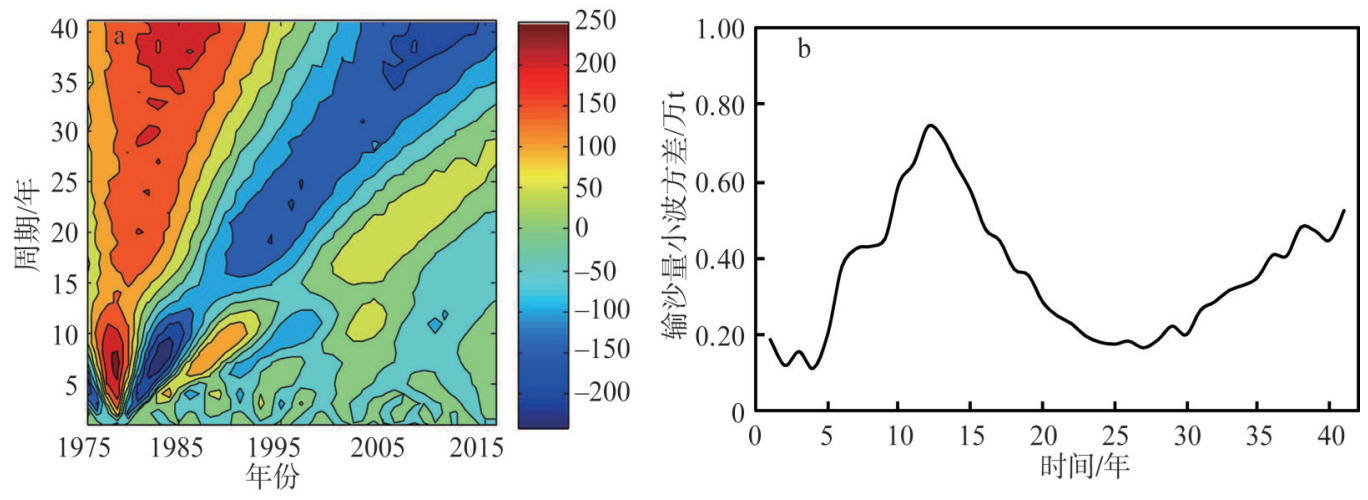

图 6 年输沙量小波周期图及方差变化

Fig. 6 Wavelet periodic diagram and variance change of annual average sediment discharge
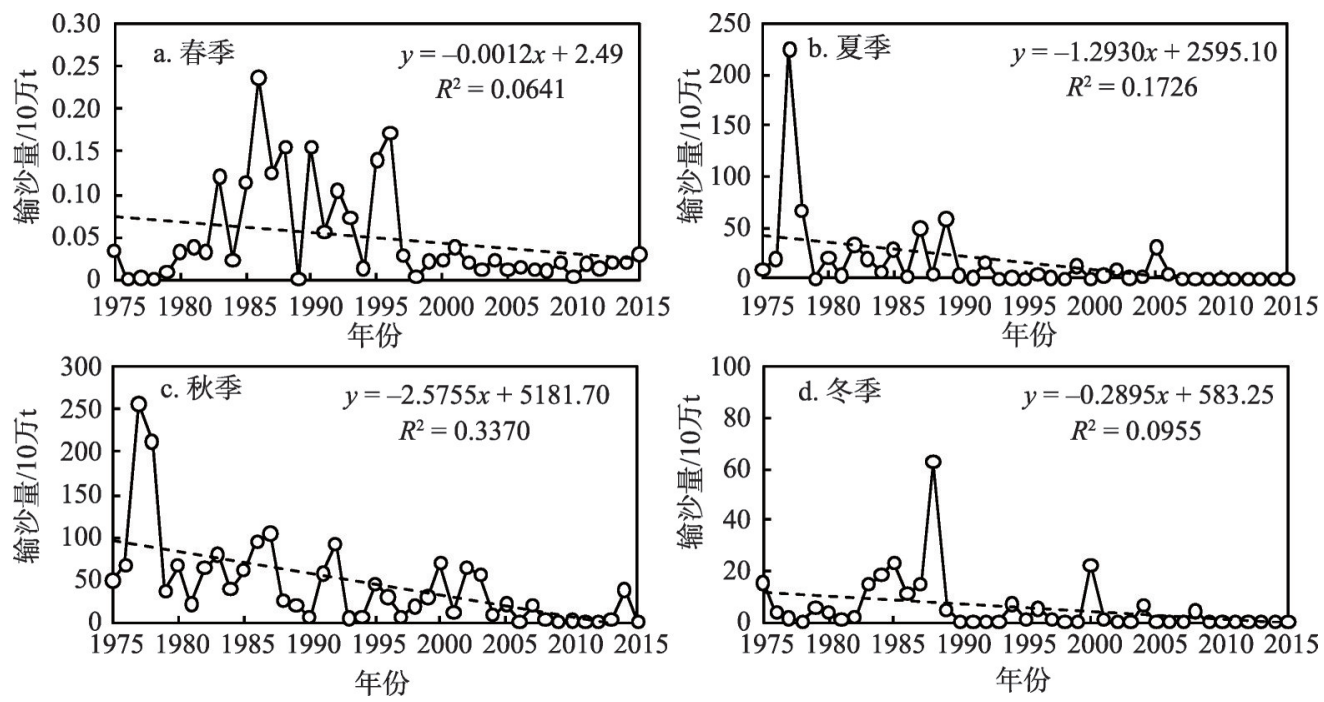

图 7 流域多年输沙量季节径流量变化

Fig. 7 Seasonal sediment discharge change of multi-year runoff in Tongzi River Basin

\section{表 4 流域季节平均输沙量变化趋势及其检验}

Table 4 Trend of seasonal average sediment discharge and its test in Tongzi River Basin

\begin{tabular}{|c|c|c|c|c|c|c|c|c|}
\hline \multirow{2}{*}{ 季节 } & \multicolumn{4}{|c|}{ Kendall秩相关系数 } & \multirow{2}{*}{ 累积滤波器法 } & \multirow{2}{*}{ Hurst 指数 } & \multirow{2}{*}{ 未来趋势 } & \multirow{2}{*}{ 持续时间/年 } \\
\hline & $M$ 值 & 趋势 & $M a=0.05$ & 显著性 & & & & \\
\hline 春季 & 1.35 & 下降 & 1.96 & 不显著 & 减少 & 0.96 & 持续减少 & - \\
\hline 夏季 & 4.67 & 下降 & 1.96 & 显著 & 减少 & 0.73 & 持续减少 & 8 \\
\hline 秋季 & 4.70 & 下降 & 1.96 & 显著 & 减少 & 0.77 & 持续减少 & - \\
\hline 冬季 & 4.25 & 下降 & 1.96 & 显著 & 减少 & 0.79 & 持续减少 & - \\
\hline
\end{tabular}

著性水平，而且还达到了显著性水平 $Z$ 值为 $2.57(P=0.001)$ 的显著性水平，春季的多年 输沙量的 $M$ 值为 1.35 , 没有达到 $Z$ 值为 $1.96(P=0.05)$ 的显著性水平, 说明桐梓河流域的 输沙量自 1975 年以来, 夏季、秋季和冬季的输沙量呈现出显著下降的趋势, 而春季的输 沙量没有达到显著下降水平。本研究使用Hurst 指数方法对桐梓河流域春季、夏季、秋季 
以及冬季输沙量的未来趋势进行预测（图 8), 预测出的 Hurst 指数值分别为 $H=0.96$ 、 $H=0.73 、 H=0.77$ 和 $H=0.79$, 其值都大于 0.50 , 表明流域四季输沙量的变化趋势与历史 时期保持一致，其中春季的 Hurst 指数值最大，代表未来时期春季的输沙量的持续性降低 趋势最为明显。结合 $M$ 值与 $H$ 值的分析结果表明, 未来时期内, 夏季、秋季和冬季的输 沙量将会呈现出持续且显著减少趋势，而春季的输沙量将会呈现出持续但不显著减少趋 势。从桐梓河流域多年季节输沙量变化持续性周期图中可知春季、秋季以及冬季输沙量 时间序列对初始条件不存在依赖性，夏季输沙时间序列的持续性时间在 8 年尺度上出现 最大的循环周期，说明夏季输沙量时间序列系统对初始条件的平均记忆长度的时间为 8 年, 8 年以后夏季的输沙量可能呈现出增加趋势。

\section{5 气候变化和人类活动对桐梓河流域二郎坝输沙量的作用辨析}

以桐梓河流域输沙量的突变点 1989 年为分界点, 将流域输沙量过程、降水量过程以
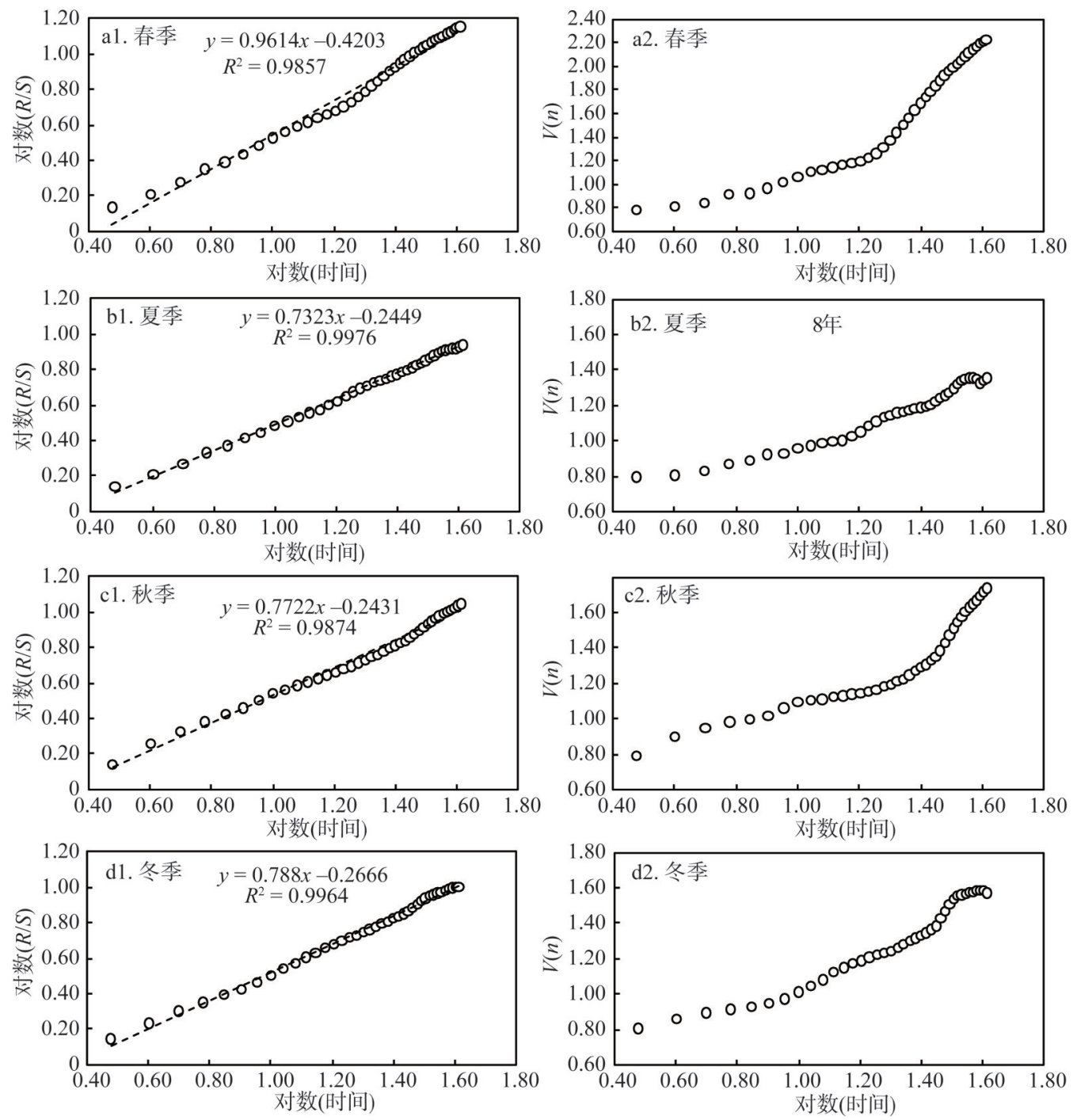

图 8 桐梓河流域季节平均输沙量变化 Hurst 指数及其持续性周期

Fig. 8 Hurst index and its continuous cycle of seasonal average sediment discharge change in Tongzi River Basin 
及蒸散量变化过程分别划分为两个时期（1975-1989年 TA）和（1990-2015年 TB), 分别 对年份与累积泥沙量、累积降水量与累积蒸发量进行线性回归分析, 可以得到关于泥沙 累积量、降水累积量以及蒸散发累积量的相关关系方程式，其相关系数都达到了 0.99 显 著水平以上。此外, 显著性水平 $P$ 也都小于 0.001 , 说明达到了极显著相关水平, 因此通 过分析可知突变点以前的泥沙量变化基本受制于气候因素制约, 而后则主要受到气候变化 和人类活动的共同制约。通过计算可以得到桐梓河流域泥沙量、降水量和蒸发量在突变点 前后的斜率（表 5、表 6)。由计算结果可知，如果不考虑蒸发量，降水量和人类活动对 桐梓河流域输沙量的贡献在 TB 时期分别达到 4.87\%和 $95.14 \%$; 如果考虑蒸发量对桐梓河 流域泥沙量的影响，则人类活动对桐梓河流域输沙量变化的贡献率在 TB 时期会增加到 $98.65 \%$ 。结合上文中的降水变化趋势可知，桐梓河流域 1975-2015 年降水量呈现出不显 著下降趋势, 而流域泥沙量则呈现出显著下降趋势, 说明流域泥沙量的减少不是受到降 水量的直接驱动及其控制, 而是主要受到人类活动的控制。

表 5 桐梓河流域不同年份与累积量相互 关系式的斜率

Table 5 Slopes of correlations between different years and cumulants in Tongzi River Basin

\begin{tabular}{ccc}
\hline 时期 & 1975-1989年(TA) & $1990-2015$ 年(TB) \\
\hline 累积泥沙量斜率 $/$ 亿 $\mathrm{m}^{3}$ & 119.04 & 29.60 \\
累积降水量斜率 $/ \mathrm{mm}$ & 845.39 & 814.51 \\
累积蒸散量斜率 $/ \mathrm{mm}$ & 696.78 & 678.42 \\
\hline
\end{tabular}

表 6 气候变化和人类活动对桐梓河流域输沙 量变化的贡献率

Table 6 Contribution rate of climate change and human activities to sediment discharge change in Tongzi River Basin

\begin{tabular}{cc}
\hline 影响因子 & TB 与 TA 比较 \\
\hline$C_{p}$ & 4.87 \\
$C_{e}$ & -3.51 \\
$C_{e}+C_{h}$ & 95.14 \\
$C_{h}$ & 98.65 \\
\hline
\end{tabular}

\section{3 结论与讨论}

\section{1 结论}

本文以桐梓河流域为研究对象，基于二郎坝水文监测断面的长时间序列的水文气象 监测数据, 通过累积距平法、Morlet 小波分析和 Hurst 指数定量分析了流域 1975-2015 年 以来输沙量的演变特征和未来趋势, 并应用累积量斜率变化率比较法定量评估了流域 气候变化和人类活动对输沙量的贡献比例 (图9)。研究结果表明:

(1) 年输沙量呈现出极显著减少趋势 $(P<0.001)$, 减少速率为 -4.13 万 $\mathrm{t} / \mathrm{a}$ 。输沙量未 来变化呈持续递减的趋势, 但在 10 年后可能呈现出增加趋势。季节输沙量均呈现出持续 性减少趋势, 其中夏季、秋季和冬季的输沙量呈现出显著下降的趋势, 而春季的输沙量 呈不显著下降趋势。流域夏季输沙量存在 8 年的循环周期, 夏季的输沙量在 8 年后可能呈 现出增加趋势，而其他季节则不存在循环周期。

(2) 年输沙量的突变年份为 1989 年, 其中 1989 年以前输沙量呈现上升趋势, 1989 年以后呈现减少趋势, 突变年份后输沙量较突变年份前减少了 $76.82 \%$, 突变年份后输沙 量呈现出显著减少趋势。

（3）年输沙量存在 12 年的主周期，形成了两个高震荡周期和一个低震荡中心，高震 荡周期位于 1976-1979年及 1986-1992 年，输沙量在该时期内呈现出正相位；而 19791985年输沙量呈现出负相位。

（4）以 1975-1989为基准期, 降水量和人类活动对桐梓河流域输沙量的贡献在 1990- 
2015 年分别达到 $4.87 \%$ 和 $95.14 \%$ ；如果考虑 蒸发量对桐梓河流域输沙量的影响，则人类 活动对桐梓河流域输沙量变化的贡献率在 1990-2015 年会增加到 98.65\%。流域泥沙量的 减少在 1975-2015 年的变化由人类活动引起, 而不是受到降水量的控制，人类活动导致输 沙量每年减少 1.57 万 $\mathrm{t}$ 。

\section{2 讨论}

非喀斯特流域人类活动对径流量变化的 主要影响方式是修建水库、大坝和跨流域引 水工程对径流量进行拦蓄滞留。人类活动是 非喀斯特流域径流量变化最主要的影响因 素，贡献率高达 70\% 100\%，而气候因素的 贡献率偏低，大部分低于 $50 \%$ 。Wang 等 ${ }^{[30]}$ 以 黄土高原 60 年以来的降水、泥沙和径流等水 文数据为基础, 采用相关数理统计方法揭示 了流域产流能力的降低直接导致 58\%的输沙 量减少, 坝库、梯田等人类活动 (占 $54 \%$ ) 是 1970-1990年代黄土高原输沙量减少的主要 原因。2000年以后, 由于退耕还林还草等植被 恢复措施的实行, 生态工程对区域土壤的流失 起到了巨大的贡献作用, 占 $57 \%$ 。因此, 坡面 和沟道的生物和工程等多种措施共同作用把

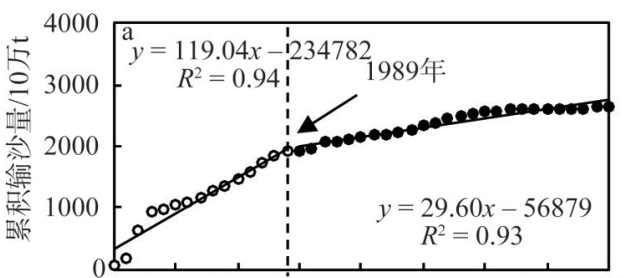

197519801985199019952000200520102015 年份
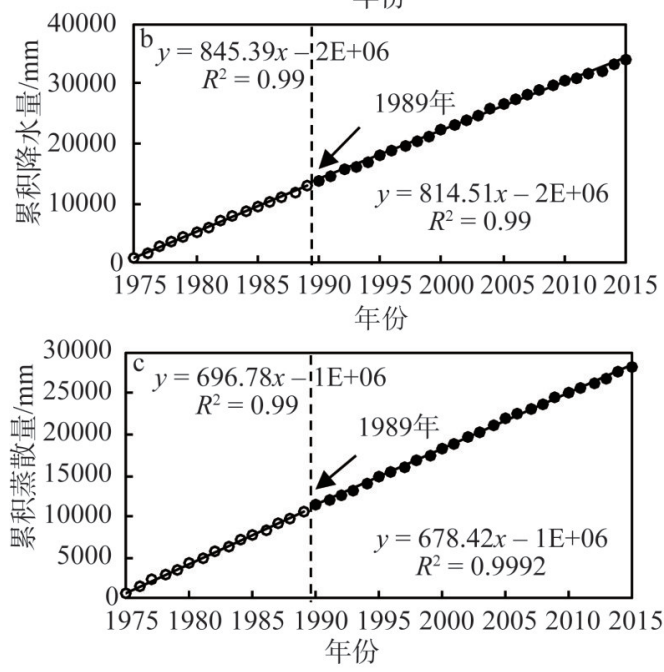

图 9 桐梓河流域年份与累积输沙量、累积降水 量、累积潜在蒸散量之间的关系

Fig. 9 Relationship between cumulative sediment discharge, cumulative precipitation and cumulative potential evapotranspiration in Tongzi River Basin 黄河输沙量控制到了人类活动影响之前的程

度。根据王随继等 ${ }^{[28]}$ 在黄河流域的研究结果显示, 如果考虑蒸散量的影响, 则人类活动 (坝库等工程措施）对黄河中游区间产流量变化的贡献率在变异期和措施期分别增大到 $91.74 \%$ 和 $93.41 \%$ 。桐梓河流域属于赤水河流域（长江流域支流）最大的支流，人类活动 是桐梓河流域径流量减少的主要因素。根据王雁等 ${ }^{\left[{ }^{11}\right.}$ 对长江流域的研究, 2000 年之后, 人类活动如下垫面变化的变化对流域水文过程的贡献率上升到 $73 \%$ 。代稳等 ${ }^{[32]}$ 的研究结 果显示，1969-2005 年间，枝城、沙市、监利、城陵矶和螺山站人类活动对径流变化影响 的贡献率分别为 $85.68 \% 、 50.89 \% 、 84.78 \%$ 、 $89.81 \%$ 和 $68.39 \% ； 2006-2014$ 年人类活动的 贡献率分别为 $88.40 \% 、 59.47 \% 、 82.86 \% 、 80.03 \%$ 、 $63.63 \%$ 。相关研究表明人类活动是长 江流域径流量变化的主要原因的主导因素，且影响很高，与本文的研究结果一致。

由本研究的结果可知，桐梓河流域 1975-2015 年降水量呈现出不显著下降趋势，而流 域泥沙量则呈现出显著下降趋势, 说明流域泥沙量的减少不受降水量的直接控制, 而是 主要受到人类活动的控制。桐梓河流域自 1989 年之后兴建的小型水库等水利设施, 这 些工程及其水利设施的实施，增加了流域的水域面积，同时使得流域的蒸散量呈现出 增加趋势。因此，这些水利工程的存在，増加了水资源利用，造成径流减少，对流域的 输沙产生了直接的影响。此外, 由于石漠化工程项目的大量实施, 加强了地表坡面水土 保护措施，桐梓河流域在实现生态恢复的同时，也缓减了水土流失作用（图 10）。由 Mo- 
dis13Q1 植被 NDVI 的监测结果（图 1）可知，流域植被 NDVI呈现出增加趋势，且增加 的区域所占的面积达到 $78.2 \%$, 这些人类活动对喀斯特流域输沙量变化的影响主要是通 过植被措施在喀斯特坡面的拦截作用减小了坡面产流量，导致径流集流面积大大减小， 河道输沙能力降低。
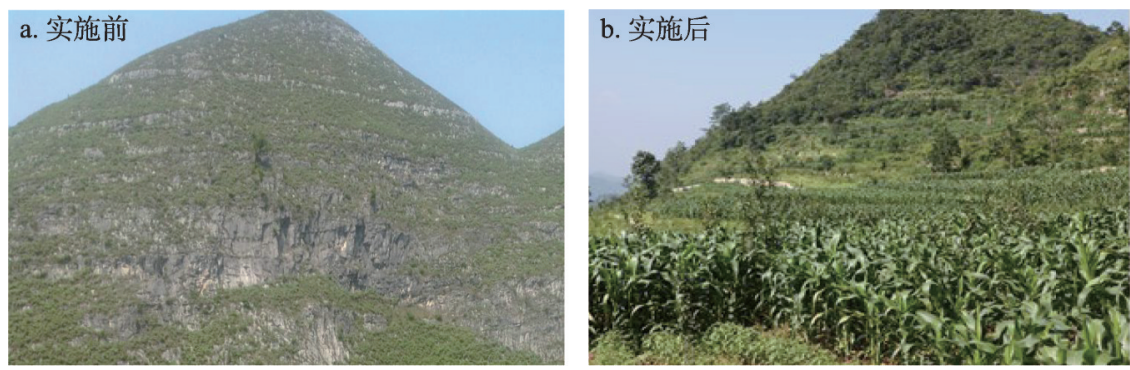

图 10 桐梓河流域（局部）退耕还林、石漠化工程实施前后景观格局对比

Fig. 10 Comparison of landscape patterns before and after the implementation of the project of converting farmland to forests and rocky desertification in Tongzi River Basin

\section{参考文献(References):}

[1] 王绍武, 叶瑾琳. 近百年全球气候变暖的分析. 大气科学, 1995, 19(5): 545-553. [WANG S W, YE J L. An analysis of global warming during the last one hundred years. Scientia Atmospherica Sinica, 1995, 19(5): 545-553.]

[2] 刘晓东, 安芷生, 方建刚, 等. 全球气候变暖条件下黄河流域降水的可能变化. 地理科学, 2002, 22(5): 513-519. [LIU X D, AN Z S, FANG J G, et al. Possible variations of precipitation over the Yellow River Valley under the global-warming conditions. Scientia Geographica Sinica, 2002, 22(5): 513-519.]

[3] 曹梓豪, 赵清贺, 丁圣彦, 等. 坡度和植被盖度对河岸坡面侵蚀产沙特征的影响. 自然资源学报, 2017, 32(11): 18921904. [CAO Z H, ZHAO Q H, DING S Y, et al. Effect of slope gradient and vegetation cover on sediment yielding characteristics of the riparian slope. Journal of Natural Resources, 2017, 32(11): 1892-1904.]

[4] RITA C S V R, RODRIGUEZ D A, TOMASELLA J, et al. Response of the river discharge in the Tocantins River Basin, Brazil, to environmental changes and the associated effects on the energy potential. Regional Environmental Change, 2019, 19(1): 193-204.

[5] STOCKER T. IPCC, 2013: Technical Summary. In: Climate Change 2013: The Physical Science Basis. Contribution of Working Group I to the Fifth Assessment Report of the Intergovernmental Panel on Climate Change. Computational Geometry, 2013, 18(2): 95-123.

[6] LI Z, ZHENG F L, LIU W Z, et al. Spatial distribution and temporal trends of extreme temperature and precipitation events on the Loess Plateau of China during 1961-2007. Quaternary International, 2010, 226(1): 92-100.

[7] HE D, ZHANG K, TANG J, et al. Using fecal sterols to assess dynamics of sewage input in sediments along a human-impacted river-estuary system in eastern China. Science of the Total Environment, 2018, 636: 787-797.

[8] 赵阳, 曹文洪, 谢刚, 等. 黄土丘陵区小流域土地覆被变化对径流产沙量的影响. 中国环境科学, 2014, 34(8): 21112117. [ZHAO Y, CAO W H, XIE G, et al. Effect of land cover change on runoff and sediment yield of small watershed in loess hilly-gully region. China Environmental Science, 2014, 34(8): 2111-2117.]

[9] MA X, ZHUANG C, WANG Z, et al. Positive leader velocity and discharge current considering leader branching under different air pressures. IEEE Transactions on Plasma Science, 2019, (99): 1-5.

[10] 顾朝军, 穆兴民, 孙文义, 等. 极端暴雨洪水及侵蚀产沙对延河流域植被恢复响应的比较研究. 自然资源学报, 2017, 32(10): 1755-1767. [GU C J, MU X M, SUN W Y, et al. Comparative analysis of the responses of rainstorm flood and sediment yield to vegetation rehabilitation in the Yanhe River Basin. Journal of Natural Resources, 2017, 32(10): 1755-1767.]

[11] 吴丽, 张爱静. 气候变化和人类活动对大凌河上游流域径流的影响. 水利水电科技进展, 2016, 36(2): 10-15. [WU L, ZHAGN A J. Effects of climate change and human activities on runoff in upper Daling River Basin. Advances in Science and Technology of Water Resources, 2016, 36(2): 10-15.] 
[12] WALLING D E, FANG D. Recent trends in the suspended sediment loads of the world's rivers. Global \& Planetary Change, 2003, 39(1): 111-126.

[13] WALLING D E. Human impact on land-ocean sediment transfer by the world's rivers. Geomorphology, 2006, 79(3): 192-216.

[14] HUNTINGTON T G. Evidence for intensification of the global water cycle: Review and synthesis. Journal of Hydrology, 2006, 319(1): 83-95.

[15] LU X X, RAN L S, LIU S, et al. Sediment loads response to climate change: A preliminary study of eight large Chinese rivers. International Journal of Sediment Research, 2013, 28(1): 1-14.

[16] 姚文艺, 手大川, 陈江南. 黄河流域近期水沙变化及其趋势预测. 水科学进展, 2013, 24(5): 607-616. [YAO W Y, RAN D C, CHEN J N. Recent changes in runoff and sediment regimes and future projections in the Yellow River Basin. Advances in Water Science, 2013, 24(5): 607-616.]

[17] 郑培龙, 李云霞, 寇馨月, 等. 黄土高原藉河流域径流对气候和土地利用变化的响应. 水土保持通报, 2016, 36(2): 250-253. [ZHENG P L, LI Y X, KOU X Y, et al. Effects of climate variation and land use change on streamflow in Jiehe Watershed of Loess Plateau. Bulletin of Soil and Water Conservation, 2016, 36(2): 250-253.]

[18] 何旭强, 张勃, 孙力炜, 等. 气候变化和人类活动对黑河上中游径流量变化的贡献率. 生态学杂志, 2012, 31(11): 2884-2890. [HE X Q, ZHAGN B, SUN L W, et al. Contribution rates of climate change and human activity on the streamflow in upper and middle reaches of Heihe River Basin. Chinese Journal of Ecology, 2012, 31(11): 2884-2890.]

[19] 孔兰, 梁虹, 黄法苏, 等. 基于喀斯特流域径流量多时间尺度小波分析. 人民长江, 2008, 39(5): 17-18. [KONG L, LIANG H, HUANG F S, et al. Multi-time-scale analysis for runoff in karst basin based on wave-let transfer. Chinese Yangtze River, 2008, 39(5): 17-18.]

[20] WU L H, WANG S J, BAI X Y, et al. Quantitative assessment of the impacts of climate change and human activities on runoff change in a typical karst watershed, SW China. Science of the Total Environment, 2017, 601-602: 1449-1465.

[21] LUO G J, WANG S J, BAI X Y, et al. Delineating small karst watersheds based on digital elevation model and eco-hydrogeological principles. Solid Earth, 2016, 7(2): 1-28.

[22] PENG T, WANG S J. Effects of land use, land cover and rainfall regimes on the surface runoff and soil loss on karst slopes in Southwest China. Catena, 2012: 53-62.

[23] 李野, 鲍新华, 王泰涵, 等. 白龙江上游径流变化特征及其与人类活动的关系. 科学技术与工程, 2016, 16(27): 8893. [LI Y, BAO X H, WANG T H, et al. Runoff variation characteristics and its relationship with human activities in upper reaches of Bailong River Basin. Science Technology and Engineering, 2016, 16(27): 88-93.]

[24] 任婧宇, 彭守璋, 曹扬, 等. 1901-2014年黄土高原区域气候变化时空分布特征. 自然资源学报, 2018, 33(4): 621-633. [REN J Y, PENG S Z, CAO Y, et al. Spatiotemporal distribution characteristics of climate change in the Loess Plateau from 1901 to 2014. Journal of Natural Resources, 2018, 33(4): 621-633.]

[25] 陈伏龙, 王怡璇, 吴泽斌, 等. 气候变化和人类活动对干旱区内陆河径流量的影响: 以新疆玛纳斯河流域肯斯瓦特 水文为例. 干旱区研究, 2015, 32(4): 692-697. [CHEN F L, WANG Y X, WU Z B, et al. Impacts of climate change and human activities on runoff of continental river in arid areas: Taking Kensiwate Hydrological station in Xinjiang Manas River Basin as an example. Arid Zone Research, 2015, 32(4): 692-697.]

[26] HURST H E. Closure to long-term storage capacity of reservoirs by H. E. Hurst. Transactions of the American Society of Civil Engineers, 2013, 116: 804-808.

[27] MANDELBROT B B, WALLIS J R. Robustness of the rescaled range R/S in the measurement of noncyclic long run statistical dependence. Water Resources Research, 1969, 5(5): 967-988.

[28] 王随继, 李玲, 颜明. 气候和人类活动对黄河中游区间产流量变化的贡献率. 地理研究, 2013, 32(3): $395-402$. [WANG S J, LI L, YAN M. The contributions of climate change and human activities to the runoff yield changes in the middle Yellow River Basin. Geographical Research, 2013, 32(3): 395-402.]

[29] NEUPAUER R M, POWELL K L. A fully-anisotropic Morlet wavelet to identify dominant orientations in a porous medium. Computers \& Geosciences, 2005, 31(4): 465-471.

[30] WANG S, FU B J, PIAO S, et al. Reduced sediment transport in the Yellow River due to anthropogenic changes. Nature Geoscience, 2015, 9(1): 38-41.

[31] 王雁, 丁永建, 叶柏生, 等. 黄河与长江流域水资源变化原因. 中国科学: 地球科学, 2013, (7): 1207-1219. [WANG Y, DING Y J, YE B S, et al. Contributions of climate and human activities to changes in runoff of the Yellow and Yangtze rivers from 1950 to 2008. Science China: Earth Sciences, 2013, 56: 1398-1412.]

[32] 代稳, 吕殿青, 李景保, 等. 气候变化和人类活动对长江中游径流量变化影响分析. 冰川冻土, 2016, 38(2): 488-497. 
[DAI W, LYU D Q, LI J B, et al. The effect of climate change and human activities on runoff in the middle reaches of the Yangtze River. Journal of Glaciology and Geocryology, 2016, 38(2): 488-497.]

\title{
Sediment transport variation and its response to climate and human activities in Tongzi River Basin
}

\author{
TIAN Yi-chao ${ }^{1,2,3,4}$, WANG Shi-jie², BAI Xiao-yong ${ }^{2}$, ZHANG Qiang ${ }^{1}$, TAO Jin', \\ ZHANG Ya-li', HUANG Hu ${ }^{4}$, LIANG Ming-zhong ${ }^{4}$, ZHOU Guo-qing ${ }^{5}$, LAO Yan-ling ${ }^{1}$ \\ (1. College of Resources and Environment, Qinzhou 535000, Guangxi, China; 2. State Key Laboratory of \\ Environmental Geochemistry, Institute of Geochemistry, Chinese Academy of Sciences, Guiyang 550081, China; \\ 3. Key Laboratory of Marine Geographic Information Resources Development and Utilization, Qinzhou 535000, \\ Guangxi, China; 4. Guangxi Key Laboratory of Beibu Gulf Marine Biodiversity Conservation, Beibu Gulf \\ University, Qinzhou 535000, Guangxi, China; 5. Guangxi Key Laboratory for Geospatial Informatics and \\ Geomatics Engineering, Guilin University of Technology, Guilin 541004, Guangxi, China)
}

\begin{abstract}
Based on the long time series data of annual precipitation, evapotranspiration and sediment transport of Erlangba Hydrological Station in Tongzi River Basin from 1975 to 2015, the evolution process and future trend of sediment transport in the past 40 years were quantitatively analyzed by the methods of cumulative anomaly, Morlet wavelet analysis and Hurst index, and the contribution rates of climate change and human activities to sediment transport in the study area were quantitatively assessed by the cumulative slope rate change comparison method. The results indicated that: (1) In the past 40 years, the precipitation in the basin ranged from $608.10 \mathrm{~mm}$ to $1132.70 \mathrm{~mm}$, with an average of $829.00 \mathrm{~mm}$. And the precipitation showed no significant decreasing trend, with an average annual decrease of $-3.10 \mathrm{~mm} / \mathrm{a}$. (2) The annual sediment transport in the basin ranged from 0.44 to 478.01 million tons, with an average of 646.8 million tons. And it showed a very significant decreasing trend, with a reduction rate of $-413000 \mathrm{t} / \mathrm{a}$. In the future, sediment transport in the basin will continue to decrease, but it is likely to increase after 10 years. (3) In 1989, the sediment discharge in the basin changed abruptly. Before 1989, it showed an upward trend. After 1989, it showed a significant downward trend. The sediment discharge after the abrupt year decreased by $76.82 \%$ compared with that before the abrupt year. (4) The sediment discharge had a 12-year interdecadal oscillation period, forming two high oscillation periods and a low oscillation center. The high oscillation period was observed in 1976-1979 and 1986-1992, and the low oscillation period was found in 1979-1985. (5) The sediment transport in summer showed an increasing trend after 8 years, while there was no continuous cycle in other seasons. (6) Based on the period from 1975 to 1989, the contributions of precipitation and human activities to the sediment transport of Tongzi River Basin reached $4.8651 \%$ and $95.1385 \%$, respectively in the period from 1989 to 2015 . If the influence of evaporation on the sediment transport of the study area was taken into account, the contribution of human activities to the change of runoff of this basin would increase to $98.65 \%$ from 1989 to 2015. The decrease of sediment transport in the basin from 1990 to 2015 was mainly controlled by human activities, which reduced sediment transport by 157 thousand tons annually.
\end{abstract}

Keywords: sediment transport; climate change; human activities; response; Tongzi River Basin 